\title{
Loggerhead turtle Caretta caretta density and abundance in Chesapeake Bay and the temperate ocean waters of the southern portion of the Mid-Atlantic Bight
}

\author{
Susan G. Barco ${ }^{1,2, *}$, M. Louise Burt ${ }^{3}$, Robert A. DiGiovanni Jr. ${ }^{4}$, W. Mark Swingle ${ }^{1}$, \\ Amanda S. Williard ${ }^{2}$ \\ ${ }^{1}$ Virginia Aquarium \& Marine Science Center, Virginia Beach, VA 23451, USA \\ ${ }^{2}$ Department of Biology and Marine Biology, University of North Carolina Wilmington, Wilmington, NC 28416, USA \\ ${ }^{3}$ Centre for Research into Ecological and Environmental Modelling, University of St Andrews, St. Andrews KY16 9LZ, UK \\ ${ }^{4}$ Atlantic Marine Conservation Society, Hampton Bays, NY 11946, USA
}

\begin{abstract}
We conducted aerial surveys of sea turtles in 2011 and 2012, incorporating corrections for perception and availability bias in Chesapeake Bay and near-shore continental shelf waters of the Mid-Atlantic Bight off the US states of Virginia and Maryland. Results of these surveys and ancillary research to determine surface times for loggerhead turtles provide us with a new baseline population estimate for turtles in the region. Prior surveys were conducted in Chesapeake Bay in the mid-1980s and early 2000s, and in ocean waters in the late 1970s and early 1980s. Although comparison of density estimates not corrected for availability between prior surveys and this effort suggests that the population of sea turtles, especially loggerhead turtles, is higher than previous estimates, differences between surveys may be the result of survey methodologies and cannot be assumed to be true changes in density. Surface time for availability corrections was calculated using dive summaries from satellite telemetry on 27 loggerhead turtles tracked between 2011 and 2015. We calculated stratified seasonal availability corrections for bay and ocean waters based on assumed differences in turtle behavior and water clarity between the 2 habitats. For each habitat, we provided seasonal corrections for 3 detection depth bins (shallow, moderate, and deep) to account for differences in sub-surface detection ranges. Differences and trends toward differences among availability corrections underscore the need to better understand the many variables that affect surface time for sea turtles in temperate waters, and the effect that availability has on abundance and density estimates.
\end{abstract}

KEY WORDS: Caretta caretta - Loggerhead - Sea turtle · Distribution · Distance sampling • Availability bias $\cdot$ Satellite tracking

\section{INTRODUCTION}

In the United States (US), trends in loggerhead turtle Caretta caretta populations are primarily assessed by analyzing the number of nests and nesting females at index sites (NMFS \& USFWS 2008, Witherington et al. 2009, Ehrhart et al. 2014, Lamont et al.

\footnotetext{
*Corresponding author: sgbarco@virginiaaquarium.com
}

2014). However, nesting beach data do not provide information on the status of younger age classes, and monitoring programs to assess in-water abundance are also necessary in order to address recovery objectives (NMFS \& USFWS 2008). Loggerhead turtles are considered threatened under the US Endangered Species Act (ESA), although the North-

() The authors 2018. Open Access under Creative Commons by Attribution Licence. Use, distribution and reproduction are unrestricted. Authors and original publication must be credited. 
west Atlantic subpopulation has been listed as Least Concern since 2001 on the IUCN Red List (NMFS 2011a, Casale \& Turner 2017). There has been no coastal critical habitat designated for loggerhead turtles north of North Carolina by the National Marine Fisheries Service (NMFS 2014), despite recognition of Chesapeake Bay, the largest estuary on the Atlantic coast of the US, as an important temperate foraging area for juvenile and sub-adult loggerhead turtles (Lutcavage \& Musick 1985, Keinath et al. 1987, Musick \& Limpus 1997, NMFS \& USFWS 2008). The southern Mid-Atlantic Bight (MAB), which includes Chesapeake Bay, is also a foraging area for adult male and post-nesting female loggerhead turtles that travel to the MAB from breeding grounds in the southeastern US (Arendt et al. 2012, Ceriani et al. 2012, 2014, Griffith et al. 2013). Sea turtles in this region face a variety of threats, including injury or mortality from vessel strikes, entanglement or entrapment in fishing gear, ingestion of gear and debris, cold stunning, predation, and disease (George 1997, Silva et al. 2011, Barco et al. 2016). Understanding trends in population size and distribution is an essential step in managing and conserving protected marine species. The loggerhead turtle is the most common sea turtle species in Chesapeake Bay, but Kemp's ridley Lepidochelys kempii and green turtles Chelonia mydas also use this habitat (Lutcavage \& Musick 1985, Keinath et al. 1987, Musick \& Limpus 1997, Mansfield 2006). Aerial surveys to monitor abundance of sea turtles in Chesapeake Bay were last conducted from 2001 to 2004 , and results from that study indicated a 65 to $75 \%$ decline in abundance compared with estimates from surveys conducted from 1982 to 1985 and in 1991 and 1992 (Mansfield 2006). Updated information on sea turtle abundance in the region is needed in order to assess population status and the efficacy of recovery efforts for sea turtle species in the midAtlantic US.

Determining in-water abundance of highly mobile, diving marine vertebrates, such as marine mammals and sea turtles, is problematic. These animals can be detected from a ship or aircraft when they come to the surface to breathe, but are difficult to detect when underwater, especially in turbid coastal and estuarine habitats (Alves et al. 2013, 2016). Without a clear understanding of the concurrent relationship among the number of animals counted at the surface, the proportion of surface animals detected by observers, and the depth(s) below the surface at which animals can be detected from the survey platform, abundance data are significantly biased (Buckland et al. 2001, Pollock et al. 2006, Fuentes et al. 2015). These errors of detection, collectively referred to as visibility bias, can be accounted for through proper survey design and parallel studies.

Line transect distance sampling is an appropriate method to estimate abundance of sea turtles and other air breathing marine vertebrates (Marsh \& Sinclair 1989, Laake et al. 1997, Buckland et al. 2001, 2004). Observers collect information on the individual or group detected and also on the perpendicular distance from the trackline for each detection. This allows for calculation of the probability of detection at perpendicular distance $(x)$ from the trackline, $g(x)$. While robust to violation of the assumption that all animals are detected in the study area, a key assumption of line transect distance sampling is that all animals at zero distance, or those that are on the trackline are detected, i.e. $g(0)=1$ (Buckland et al. 2001). Failure of this assumption cannot be solved by data manipulation, and requires observer configuration that allows for calculation of missed animals by observers (Laake \& Borchers 2004). If not accounted for, missed detections of visible animals that occur singly or in small groups, such as sea turtles, will result in an underestimate of abundance (Marsh \& Sinclair 1989, Buckland et al. 2004, Fuentes et al. 2015). The bias, created by failure to detect visible animals at the surface, is referred to as perception bias. Failing to account for animals invisible to observers (e.g. subsurface below detection depth) will also result in an underestimate of abundance. The bias associated with non-visible or unavailable animals is called availability bias (Marsh \& Sinclair 1989, Laake et al. 1997); there is no way to account for availability of individual animals that spend most of their time subsurface, such as sea turtles, without a separate, parallel study of the species' diving behavior (Pollock et al. 2006, Borchers et al. 2013). Availability corrections are typically large for species that have long dive times relative to their time at the surface. Thus, small variations in surface time for long duration divers can result in notable variation in abundance estimates, making resolution of spatial and temporal variation in availability bias very important. Satellite telemetry allows for dive and surface time data to be collected over an extended duration, across heterogeneous habitats and seasons. Documentation of time spent at shallow, sub-surface depths where turtles may be detectable, and documentation of surface times are used to develop availability bias corrections (Laake \& Borchers 2004, Thomson et al. 2012). Additionally, if animals can be detected sub- 
surface, an estimate of how far below the surface they can be detected by aerial observers is needed in order to calculate time spent between the depth of detectability and the surface.

The objective of this project was to estimate seasonal loggerhead turtle abundance in Chesapeake Bay and the MAB off the states of Virginia (VA) and Maryland (MD) across the 6 mo per year that sea turtles consistently appear in the region (May to October). We used a combination of distance sampling aerial surveys and satellite telemetry to account for perception and availability bias in order to provide robust estimates, using repeatable methodology to develop a new baseline of abundance for loggerhead sea turtles in Chesapeake Bay and the southern midAtlantic region. Distance sampling surveys were conducted in 3 seasons: spring (May and June), summer (July and August), and fall (September and October). Our fine-scale survey compliments a broad scale effort, the Atlantic Marine Assessment Program for Protected Species (AMAPPS), that was simultane- ously conducted from shore to shelf along the Atlantic coast by a collaboration of federal agencies (NMFS 2011b). A large satellite telemetry data set also allowed us to add corrections for availability stratified by water body and season. Abundance and density estimates from this project will provide protected resources managers with updated loggerhead turtle population status given previously documented declines in Chesapeake Bay (Mansfield 2006). Finally, this project highlights the impact of applying appropriate seasonal corrections for availability in a temperate sea turtle habitat.

\section{MATERIALS AND METHODS}

\section{Aerial surveys}

The study area included coastal ocean waters of VA and MD and most of Chesapeake Bay, from the mouth in VA to latitude $38.50^{\circ} \mathrm{N}$ in $\mathrm{MD}$ (Fig. 1). We

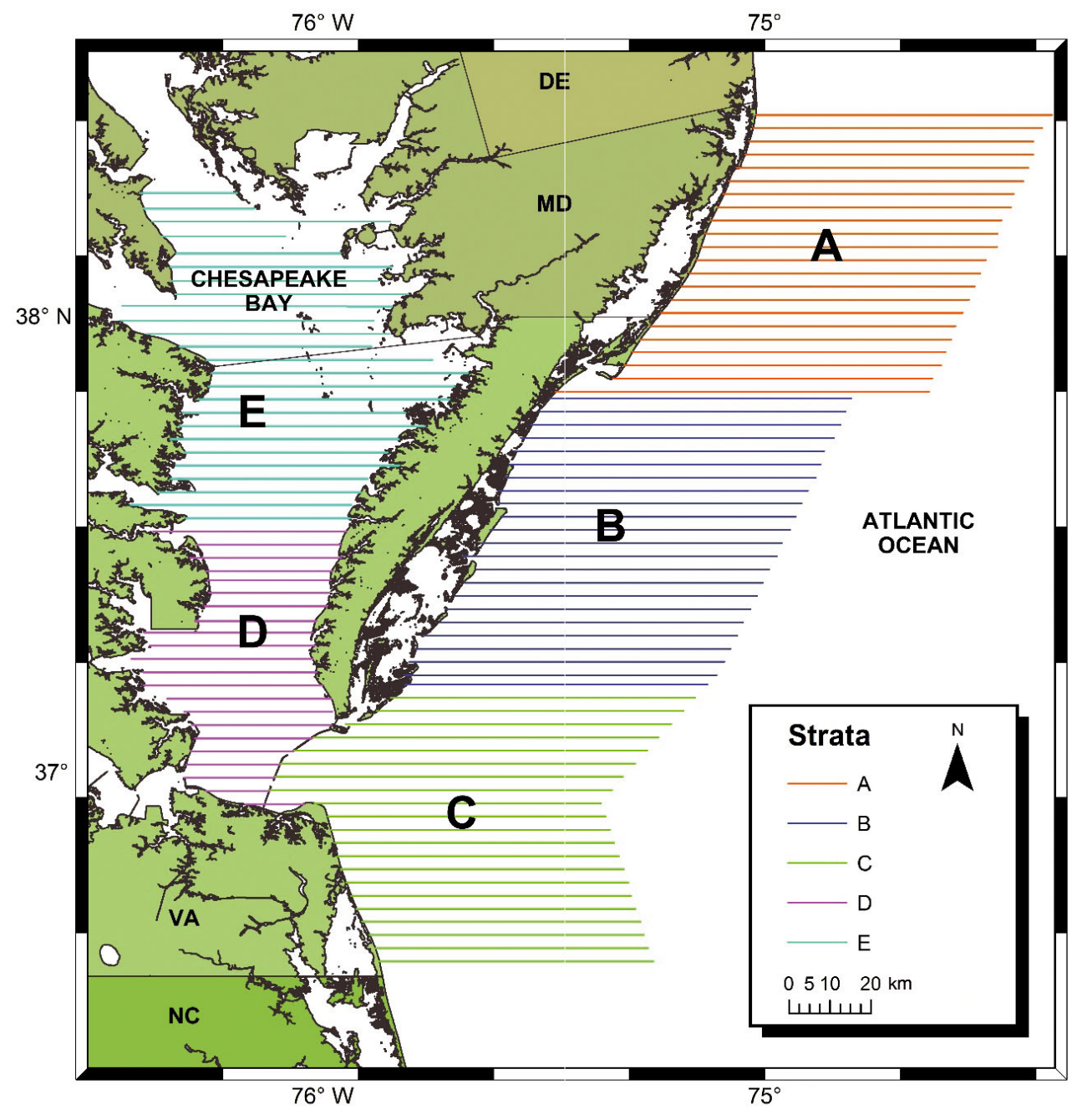

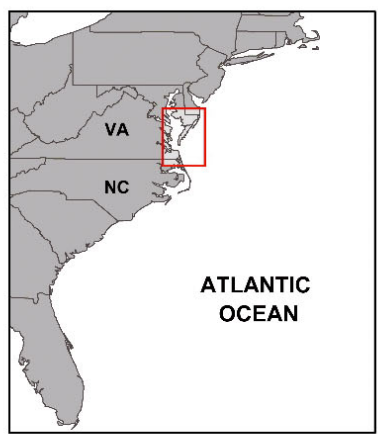

Fig. 1. Transect lines and strata (A-E) for aerial surveys conducted in waters of Virginia and Maryland, USA, from spring 2011 to summer 2012. There were 113 lines, $3.2 \mathrm{~km}$ apart and ranging from 11.4 to $71.8 \mathrm{~km}$ long 
divided the area into 5 strata, with 3 strata in the ocean $\geq 48 \mathrm{~km}$ from shore (MD ocean: stratum $\mathrm{A}_{\text {; }}$ northern VA ocean: stratum $B$; southern VA ocean: stratum C) and 2 in the lower and upper Chesapeake Bay (strata D and E, respectively). Transect lines in Chesapeake Bay were the same as previous surveys conducted by the Virginia Institute of Marine Science (VIMS), and the ocean strata lines were extended following a similar pattern (Mansfield 2006). Within the study area, there were a total of 113 east-west oriented transect lines located at approximately $3.2 \mathrm{~km}$ intervals, totaling $5441 \mathrm{~km}$ of transect (Fig. 1). There were 21 to 25 lines per stratum; transect line length ranged from 53.2 to $71.8 \mathrm{~km}$ in the ocean strata $($ mean $\pm \mathrm{SD}=58.4 \pm 4.0 \mathrm{~km}$ ) and 11.4 to $52.7 \mathrm{~km}$ in the bay strata $(33.7 \pm 10.8 \mathrm{~km}$; Table 1$)$. Assuming a total strip width of $1 \mathrm{~km}$ (500 m on either side of the aircraft), the designed coverage probability (covered area/survey area) was approximately $32 \%$. We use the term 'transect lines' to indicate the lines between the mapped points of the survey design, and the term 'trackline' to refer to the actual track of the aircraft during surveys recorded using a global positioning system (GPS).

The initial survey design included a total of 9 discrete survey periods, conducted in late spring (May and June), summer (July and August) and early fall (September and October) in each of 3 yr (2011, 2012 , 2013). A survey was completed when we flew 4 or more transect lines per stratum during a survey period. At the beginning of each survey day, the team leader and pilots determined the stratum in which to start, based on weather, airspace closures, previous transect lines completed etc. The team used a random number to determine the starting line number, and lines were surveyed systematically, every fourth line from the randomly generated line in order to cover at least 4 transect lines in each of the 5 strata.

Table 1. Transect line data for aerial surveys. Lines were oriented east-west and were longer in the ocean strata $(\mathrm{A}-\mathrm{C})$ than in Chesapeake Bay (D-E)

\begin{tabular}{|lcrrrr|}
\hline Stratum & $\begin{array}{c}\text { No. of } \\
\text { lines }\end{array}$ & $\begin{array}{c}\text { Mean } \\
\text { length } \\
(\mathrm{km})\end{array}$ & $\begin{array}{c}\text { SD } \\
(\mathrm{km})\end{array}$ & $\begin{array}{c}\text { Min. } \\
\text { length } \\
(\mathrm{km})\end{array}$ & $\begin{array}{c}\text { Max. } \\
\text { length } \\
(\mathrm{km})\end{array}$ \\
\hline $\mathrm{A}$ & 22 & 57.7 & 3.7 & 54.3 & 71.8 \\
$\mathrm{~B}$ & 23 & 59.1 & 1.3 & 56.5 & 61.1 \\
$\mathrm{C}$ & 21 & 58.4 & 5.8 & 53.2 & 68.9 \\
$\mathrm{D}$ & 22 & 26.0 & 7.2 & 11.4 & 37.5 \\
E & 25 & 40.4 & 8.9 & 18.4 & 52.7 \\
Survey area & 113 & 48.1 & 14.4 & 11.4 & 71.8 \\
\hline
\end{tabular}

Surveys were conducted by trained observers, and the team leader was trained in AMAPPS aerial survey methodology described below. The survey platform was a deHavilland DHC-6 Twin Otter, a twin engine fixed-wing, high-wing aircraft capable of carrying 2 pilots in accordance with National Oceanic and Atmospheric Administration (NOAA) aviation safety policies (41 CFR 102-33.155-185). The aircraft had port and starboard side bubble windows in the front, a right rear bubble window, and a belly observer position in the rear of the aircraft. There were also positions for 2 independent data recorders to enter detections and changes in sighting conditions on a laptop computer. The aircraft was configured for 2 forward observers (port and starboard) and a data recorder on one communication system (Team 1), and a second team (Team 2) consisting of a belly observer, one additional observer (either port or starboard), and a second data recorder on a separate communication system. This setup enabled the 2 teams to function independently within a single platform, essentially providing 2 independent surveys for a mark-recapture analysis to estimate perception bias. Observers on Team 1 used convex bubble windows to improve visualization below the plane. In 2011, the side observer on Team 2 looked through a floor-to-roof conventional window, but in 2012 the plane was outfitted with a (right) rear bubble window so that the Team 2 side observer had the same field of view as Team 1. There were no differences in Team 1 's field of view among the survey years. With bubble windows, side observers monitored $90^{\circ}$ on his/her side of the aircraft, from directly ahead of the aircraft to perpendicular to the aircraft. The belly observer on Team 2 was able to monitor approximately $30^{\circ}$ on either side of the track line for a $60^{\circ}$ observation window. Surveys were flown at $183 \mathrm{~m}$ altitude at an average speed of $175 \mathrm{~km} \mathrm{~h}^{-1}$. The plane, observer orientation, speed, and altitude were consistent with AMAPPS aerial surveys, some of which were conducted with the same aircraft and pilots (NMFS 2011b). Environmental data, such as sea state, glare, turbidity, cloud cover, and overall sighting quality were collected during the survey and updated as changes occurred. Surveys were not initiated if Beaufort sea state (BSS) was above 3.0, and were aborted if sea state increased during a survey to above 4.0. Presence of a sustained cloud ceiling below survey altitude and/or thunderstorms were also conditions that resulted in the crew standing down. When conditions were favorable, surveys were conducted from $90 \mathrm{~min}$ after sunrise to $90 \mathrm{~min}$ before sunset. 
Each observer monitored his/her observation area for marine animals. When an individual animal or group was detected, the observer reported a detection to the data recorder at the time when the animal/group was perpendicular to the aircraft. The observer also reported the angle of inclination to the animal/group, species (when determined), number of animals in the group (usually 1 for sea turtle detections), and swim direction. Turtle species was determined using observed morphological characteristics such as carapace size and shape (to distinguish Kemp's ridley from loggerhead turtles), head/neck size and shape (to distinguish large juvenile green from similarly sized loggerhead turtles), and carapace/skin color (to distinguish all species). Observers all had experience with the sea turtle species that occur in the mid-Atlantic region and conducted trials and compared observations during the first survey window in spring 2011. Side window observers used an inclinometer to determine angle of the sighting, and the belly window observer estimated the angle based on window marks. When a data recorder recorded a detection, aircraft altitude, speed, latitude, and longitude were automatically logged by computer. Perpendicular distance $(D)$ from the transect was calculated as: $D=A \times \tan$ (angle of inclination), where $A=$ altitude.

\section{Estimating availability bias}

\section{Detection trials}

In order to determine the depth at which a turtle could be detected by an observer during aerial surveys, we conducted a sub-surface detection trial in Chesapeake Bay on 26 June 2015. Our goal was to conduct trials in both bay and ocean strata, but we were restricted to one trial due to weather conditions and aircraft availability. The detection trial was conducted in BSS 3.0 to 3.4, with overcast skies and light rain during a portion of the trial. Qualitatively, sighting conditions were considered moderate to fair. Plywood models based on a $65 \mathrm{~cm}$ minimum straight carapace length turtle, painted to resemble juvenile loggerhead turtles, were suspended below the surface at target depths of $0.5,1.0,1.5$, and $2.0 \mathrm{~m}$ using a buoy system consisting of 1 polyball buoy (20 to $35 \mathrm{~cm}$ diameter) and three $41 \mathrm{~cm}$ long bullet buoys arranged into a square. A series of 5 square buoy systems were deployed in a dog-leg pattern along a $\sim 10 \mathrm{~km}$ line, with the polyball of the first buoy system positioned at $37.0167^{\circ} \mathrm{N}, 76.2627^{\circ} \mathrm{W}$ and the polyball of the fifth buoy system at $37.1178^{\circ} \mathrm{N}, 76.2625^{\circ} \mathrm{W}$. There was a distance of approximately $2 \mathrm{~km}$ between each buoy system. One of the buoy systems was deployed with no model suspended within the square; all other buoy systems had one model suspended sub-surface inside the square. The depth at which each model was suspended within the buoy system was randomly chosen and the models were used in the same configuration for all observations. When possible, we took the mean of the model depth before and after the trial to estimate the average depth of the model under changing current conditions. Secchi depths were recorded at each buoy system. Although we were unable to conduct a detection trial in the ocean, we also collected Secchi depths in July 2015 in the ocean $32 \mathrm{~km}$ offshore and southeast of the mouth of Chesapeake Bay.

Observer configuration for the detection trials was the same as for the aerial surveys (see description of observer teams above). The plane made a total of 10 passes over the buoy systems. Passes were made from each direction (south to north and north to south) and with the buoys on each (left and right) side of the plane in order to allow for different observation direction and observer views. Pilots were instructed to fly with the buoys slightly to the right or left of the plane since survey data indicated that the side observers had lower detections directly below the aircraft than on either side of the trackline. Upon detection of a buoy system, observers were instructed to measure the angle of inclination of the polyball buoy and to count the number of turtles seen within the buoy system square. They were told that there would be 0 to 2 turtles within the buoy square. With multiple passes by the plane, each buoy system was observed multiple times by the 2 observer teams, providing us with up to 150 data points ( 5 buoy systems with 2 to 3 observers detecting the buoys on each of 10 passes).

After data were collected from observers, we matched the latitude and longitude of the detections with the polyballs, determined the distance from the trackline for each detection, and scored each detection as correct (1) or incorrect (0). If a turtle was present and the observers did not detect it, the score was 0 ; likewise, if a turtle was not present and the observers reported a turtle, the score was 0 . Also, if one turtle was present and the observers recorded more than one, the score was 0 . We then calculated the percent correct detections for each buoy system. We used the observations from the detection trials to qualitatively assess the range of depths at which turtles could be detected. 


\section{Telemetry}

From summer 2011 through fall 2015, we deployed 27 satellite-linked archival tags on loggerhead turtles that were stranded and rehabilitated $(n=16)$, captured through directed efforts (wild caught; $\mathrm{n}=$ 6), and bycaught in commercial pound nets, other net enclosures, or trawl gear associated with dredge activities $(\mathrm{n}=5)$ in VA. Straight carapace length (SCL; notch to tip) of turtles ranged from 47.5 to $99.4 \mathrm{~cm}$ (mean $\pm \mathrm{SD}=67.0 \pm 11.1 \mathrm{~cm}$ ), and mass ranged from 18.0 to $140.4 \mathrm{~kg}(49.2 \pm 25.8 \mathrm{~kg})$. Deployed tags transmitted for 7 to $505 \mathrm{~d}(176 \pm$ 137 d). Larger turtles (SCL $\geq 65 \mathrm{~cm}$; $\mathrm{n}=17$ ) were equipped with a satellite relay data logger (SRDL) 9000X tag (370 g, $10.5 \times 7 \times 4$ cm; Sea Mammal Research Unit [SMRU]), and smaller turtles (SCL < $65 \mathrm{~cm} ; \mathrm{n}=10$ ), were equipped with a SPLASH 200B $(60 \mathrm{~g}, 9.2 \times 2.5 \times 1.8 \mathrm{~cm})$, SPLASH $284 \mathrm{~A}(120 \mathrm{~g}, 7.2 \times$ $5.5 \times 3.0 \mathrm{~cm})$, or SPLASH 309A $(125 \mathrm{~g}, 7.6 \times 5.6 \times$ $3.2 \mathrm{~cm}$ ) tag (Wildlife Computers [WC]). Tags were treated with 1 to 3 coats of anti-fouling paint (PropSpeed or Interlux Micron-CF) on the body and antenna base, avoiding sensors and saltwater switches. The tags were attached to the turtles using Sika ${ }^{\mathrm{TM}}$ AnchorFix1 epoxy after the carapace was scraped clean of epibiota and dead scute material, sanded, and treated with acetone (Coyne et al. 2008). In order to reduce drag, the epoxy was molded around the tag in a teardrop shape and lightly sanded once it set (Jones et al. 2013).

The SMRU SRDL tags were fitted with an internal clock and pressure sensor with a resolution of $\sim 0.1 \mathrm{~m}$. Dive depth was recorded every $4 \mathrm{~s}$, and dive summary data were stored and transmitted in the form of time-at-depth histograms. Data were summarized in $6 \mathrm{~h}$ intervals beginning at 00:00 h UTC (20:00 h EST on the previous day), into the following $1 \mathrm{~m}$ depth bins: $0-1,1-2,2-3,3-4$, and 4-5 m. Depth bins were the same as those programmed by AMAPPS researchers developing availability estimates for loggerhead turtles so that data could be pooled for future analysis across a broader area (NMFS 2011c). In addition, the tags recorded percent time that the tag was 'dry' at the surface, with the saltwater switch inactive. Dive summaries were randomly selected for transmission to the CLS America network satellites when turtles were at the surface. The dive summaries transmitted by SMRU SRDL tags included a date-time stamp, but did not include associated location data. Location was reported separately as CLS America positions with associated location class (Hays et al. 2001) and as GPS locations. All models of
WC SPLASH tags were fitted with an internal clock and pressure sensor with $0.5 \mathrm{~m}$ resolution. Dives were summarized as time-at-depth histograms in $6 \mathrm{~h}$ intervals starting at 00:00 $\mathrm{h}$ UTC, with the following depth bins: $0 \mathrm{~m}$ (saltwater switch dry), 0-1, 1-2, 2-3, 3-4, 4-5, 5-10, 10-20, 20-30, 30-40, 40-50, 50-100, 100-150, and >150 m. Each dive summary included the CLS America position with highest location class within $24 \mathrm{~h}$ of the dive summary time period. SPLASH tags did not record GPS locations.

We used information from detection trials and dive behavior data obtained by telemetry to define surface time and refine estimates of availability. Results from the detection trials provided information on the range of depths at which turtles could be detected. Dive summary data transmitted via satellite telemetry was used to assess the proportion of time spent at depths where turtles could be detected (i.e. surface time). Dive summary data from each tag were filtered to include only those summaries that were (1) collected $>48 \mathrm{~h}$ after a turtle's release, (2) initiated at 08:00 h EST (12:00 h UTC) and 14:00 h EST (18:00 h UTC), e.g. daylight hours (when surveys took place), and (3) collected in May through October when turtles were within the study region (e.g. Chesapeake Bay and ocean waters off VA and MD to $48 \mathrm{~km}$ offshore). Location of each dive summary was defined as the best location quality Argos coordinates within $24 \mathrm{~h}$ of the mid-point of each dive summary. The locations were selected based on time stamps associated with CLS America data. Dive summaries collected outside of the survey area or time frame, based on time stamps and/or location data, were excluded from analyses. We combined the filtered dive summary data from SMRU SRDL and WC SPLASH tags into bins to represent surface time as the percent time at the air-water interface ('dry' bin for SMRU SRDL and $0 \mathrm{~m}$ for WC SPLASH). We also summarized percent time in 3 different depth ranges within which turtles may be detectable sub-surface $(0-1,0-2$, and $0-3 \mathrm{~m})$. We did not include depths below $3.0 \mathrm{~m}$ in the analyses because of the low likelihood that sea turtles could be observed below that depth in our study area.

The use of a range of detection depths for surface time estimates illustrates the impact of differences in sub-surface detectability on availability bias corrections. Thus, use of a range of availability corrections for abundance estimates allows us to assess how changes in detectability due to fluctuating environmental conditions may influence estimates. Water clarity in Chesapeake Bay changes seasonally, interannually, and with weather events. (Gallegos et al. 
2005, 2011). These conditions are not unlike conditions described in surveyed manatee (Alves et al. 2016) and dugong habitats (Pollock et al. 2006). Alves et al. (2016) described 4 subjective water transparency categories when conducting aerial surveys for manatees in Brazil. Observers in our survey recorded turbidity as a subjective environmental variable on a scale from 0 to 2, from least to most turbid. Discussions with observers revealed, however, that application of the categories among observers was neither consistent nor quantifiable. When both BSS and turbidity were low, for example in offshore waters on a calm day, observers did not feel confident in determining whether a turtle was sub-surface by centimeters or meters. Given that we were only able to conduct 1 detection trial in Chesapeake Bay during the summer and were not able to conduct detection trials in the ocean, our ability to assess how detection would change with changing environmental conditions is limited. Thus, use of a range of availability estimates based on different detection depth ranges permits an inclusive approach to estimating abundance and density of sea turtles in this region. For the remainder of this publication, we use 3 detection depth criteria to describe availability: (1) shallow detection depth $(0 \mathrm{~m}$ in bay strata; 0 to $1 \mathrm{~m}$ in ocean strata), (2) moderate detection depth (0 to $1 \mathrm{~m}$ in bay strata; 0 to $2 \mathrm{~m}$ in ocean strata), and (3) deep detection depth ( 0 to $2 \mathrm{~m}$ in bay strata; 0 to $3 \mathrm{~m}$ in ocean strata).

Ideally, surface time for availability estimates should be calculated for a time frame that corresponds with timing of the aerial surveys (Buckland et al. 2004). During our 3 yr study, seasonal aerial surveys took place over a 5 to $10 \mathrm{~d}$ period at approximately the same time each year. We conducted an analysis to determine the most appropriate time frame for surface time assessments while simultaneously maximizing the amount of available telemetry data. We limited our analysis to data collected during the summer season in Chesapeake Bay, as this is the time and region for which the greatest amount of dive summary data were available. We calculated the mean surface time of individual turtles $(n=6)$ using the 3 detection depth ranges for the following time frames: 5, 10, and $15 \mathrm{~d}$ on either side of the midsurvey date, and the full summer season (July and August).

Mean surface times for each detection depth range in each time frame were compared using a nonparametric Friedman rank sum test. When means were significantly different, we used a nonparametric Nemenyi post hoc rank pairwise comparison (Sachs 1997 ) in the R package 'PMCMR' (Pohlert 2014) to further assess significant results. We applied Bonferroni adjustment to $\mathrm{p}$-values for multiple comparisons to determine significance of the post hoc analyses (Dunn 1961). Results of statistical analyses were used to determine the longest time frame that could be used for surface time calculations.

Because fewer than $10 \%$ of the turtles transmitted dive summaries in all 3 seasons from either habitat, there were too many missing values to conduct repeated measures analyses for seasonal surface time estimates; therefore, in order to meet assumptions of a 1-way analysis such as the Kruskal-Wallis test, we reduced the data from each turtle to 1 season per habitat. We chose to keep data from the season with the highest number of dive summaries for most cases. If a turtle had the same amount of data for more than one season, we chose to keep the estimate in the season with the lower sample size. We compared seasonal availability at different detection depth ranges using a Kruskal-Wallis test. We further assessed significantly different results using the procedure described for mean surface times (see previous paragraph). All analyses were performed using $\alpha=0.05$.

Since availability data were collected from both wild and rehabilitated loggerheads, we used a Wilcoxon rank sum test to compare individual turtles' mean percent time at the surface ( 0 to $2 \mathrm{~m}$ ) by turtle source (wild or rehabilitated) within strata-season combinations where the sample size between the groups was similar and for the stratum-season combination with the largest sample size. Data were filtered as described above.

\section{Estimation of density and abundance}

In order to calculate perception bias, we combined aerial survey detection data from the 2 independent teams and designated each sighting as observed by Team 1, Team 2, or both teams. Occasionally there were discrepancies in data reported by the different teams in the duplicate detections. There did not appear to be any systematic bias in the group size or perpendicular distance estimates of the 2 teams, so where there were differences, we used the mean value for the duplicate pair. If differences occurred in the recorded species, then sightings were classified as unidentified species. For example, if 2 different species were recorded (e.g. loggerhead and green sea turtle) for a duplicate sighting, we classified it as unidentified. When one team recorded a species and the other team listed the animal as unidentified, we 
used the recorded species (e.g. loggerhead and unidentified was classified as loggerhead).

We also designated whether the sighting occurred when the observers were both looking through side windows or when one observer was looking out a side window and the other through the belly window. For abundance estimation, we eliminated detections where the angle, and hence perpendicular distance, was missing $(n=58)$. We then entered all unique sightings into Program Distance (Thomas et al. 2010; v.6.1 Beta 1 and v.2.0.6 of the 'MRDS' R library) for abundance estimation. Within each stratum, we estimated group density $\left(\hat{D}_{\mathrm{st}}\right)$ and group abundance $\left(\hat{N}_{\text {st }}\right)$ of animals available for detection as follows:

$$
\hat{D}_{\mathrm{st}}=\frac{1}{2 W L} \sum_{j=i}^{n} \frac{s_{j}}{\hat{p}_{j}} \text { and } \hat{N}_{\mathrm{st}}=A \hat{D}_{\mathrm{st}}
$$

where $A$ is the area of stratum, $w$ is the strip width (distance that the sightings were right-truncated), $L$ is the total $\mathrm{km}$ of trackline flown, $n$ is the total number of detections in the stratum and $\hat{p}_{j}$ is the estimated probability of detecting group $j$ (where $s_{j}$ is the recorded group size for group $j$, and based on markrecapture data between the 2 teams, see below). We calculated individual animal density $(D)$ and abundance $(N)$ using:

$$
\hat{D}=\frac{1}{2 W L} \sum_{j=i}^{n} \frac{s_{j}}{\hat{p}_{j}} \text { and } \hat{N}=A \hat{D}
$$

The expected group size $(E[s])$ is given by:

$$
E[s]=\frac{\hat{N}}{\hat{N}_{\mathrm{st}}} \hat{E}[s]=\frac{\hat{N}}{\hat{N}_{\mathrm{st}}}
$$

Program Distance calculated the variance of the encounter rate $(n / L)$ using the method developed by Innes et al. (2002), with adjustments developed by Fewster et al. (2009).

Having 2 teams of observers allowed us to use a mark-recapture distance sampling approach to estimate the probability of detection (Marsh \& Sinclair 1989, Laake \& Borchers 2004). Since the 2 teams acted independently, we used a model where detections were assumed to be independent at $g(0)$ (referred to as independent observer [IO] point independence). Program Distance used 2 subsidiary models to fit an IO point independence model: (1) a distance sampling (DS) model fitted to all unique sightings assuming that $g(0)=1$; and (2) a markrecapture (MR) detection function to estimate the probability of detection by at least one team at $g(0)$. The probability of detection at $g(0)$ was used to adjust the DS detection function in the first model to obtain an overall probability of detection.

For the DS model, both the hazard rate [1 $\left.\exp (x / \sigma)^{-b}\right]$ and half-normal $\left[\exp \left(-x^{2} / 2 \sigma^{2}\right)\right.$ [ functions (where $\sigma=$ scale parameter, $x=$ perpendicular distance, and $b=$ shape parameter) were considered (Buckland et al. 2001). We chose the best fit for the detection function based on Akaike's information criterion (AIC) scores. We then incorporated the effects of covariates (other than perpendicular distance) into the detection function model by setting $\sigma$ in the model to be an exponential function of the covariates (Marques \& Buckland 2004). This method allowed the covariates to affect the rate at which detection probability decreased as a function of distance, but did not allow the shape of the detection function to change. We initially included the following covariates in the model: season, strata, observer position (left, right, or center), turtle group size (usually 1, maximum 2) and BSS. Other environmental variables examined included sea surface temperature, cloud cover, glare, turbidity, and overall sighting quality. We used AIC and goodness-of-fit statistics to select the final DS model.

The MR detection function defined the probability that an animal, at given perpendicular distance with covariates $z$ (determined in the DS model), was detected by a team, $q$ (where $q=$ Team 1 or Team 2), given that it was seen by the other team, and was denoted by $p_{q \mid 3-q}(x, z)$. The MR model used the logistic form:

$$
p_{q \mid 3-q}(x, z)=\frac{\exp \left(\beta_{0}+\beta_{1} X+\sum_{k=1}^{K} \beta_{k+1} z_{k}\right)}{1+\exp \left(\beta_{0}+\beta_{1} x+\sum_{k=1}^{K} \beta_{k+1} z_{k}\right)}
$$

where $\beta_{0}, \beta_{1}, \ldots, \beta_{k+1}$ represent the parameters to be estimated, $K$ is the total number of covariates other than distance, and $k$ is 1 individual co-variate. We used the same covariates in the above model as we did in the DS model. We used AIC for MR model selection. The intercept of the MR model (averaged over all covariates) provided us with an estimate of the probability of detection on the trackline by at least one team.

Once the models were developed, we combined strata A, B, and C to estimate abundance of loggerhead turtles in the ocean portion of the study area by season, and strata D and $\mathrm{E}$ to estimate abundance of all sea turtles in Chesapeake Bay by season. There 
were too few loggerhead turtle detections to develop a species-specific estimate in the Chesapeake Bay strata for any given season. Furthermore, there were too few sightings to estimate abundance in the Chesapeake Bay strata in fall even with all species combined. We present only count data for the fall surveys in Chesapeake Bay strata.

To correct abundance estimates for turtle availability, we combined the coefficient of variation of the abundance or density estimate, $\mathrm{CV}_{\mathrm{e}}$, with the coefficient of variation of the availability estimate (e.g. surface time), $\mathrm{CV}_{\mathrm{C}}$, using the formula: $\sqrt{\mathrm{CV}_{\mathrm{e}}^{2}+\mathrm{CV}_{\mathrm{c}}^{2}}$. A range of availability corrections based on different detection depth ranges (shallow, moderate, and deep) was used to illustrate the impact that dive behavior may have on abundance and density estimates.

\section{RESULTS}

\section{Aerial surveys}

Our original study design included 3 seasonal surveys $\mathrm{yr}^{-1}$ (spring, summer, fall) for $3 \mathrm{yr}$ (2011 to 2013) for a total of 9 surveys. Due to logistic and budgetary constraints, we were limited to 5 surveys over the course of the study: 3 surveys in 2011 (spring: 22 May to 1 June, summer: 22 to 28 July, fall: 29 September to 7 October) and 2 surveys in 2012 (spring: 6 to 9 June, summer: 28 to 31 July). Weather conditions, especially in fall 2011, and areas closed to surveys due to military activity contributed to a lower realized coverage than initially planned. The survey team flew over $22530 \mathrm{~km}$ of trackline for the project (Table S1 in the Supplement at www.int-res.com/articles/suppl/n037p269_supp.pdf). Assuming a maximum total strip width of $1 \mathrm{~km}$ (500 $\mathrm{m}$ on either side of the trackline), we covered between 10 and $35 \%$ of the study area during each survey period. Low coverage in fall of 2011 (20\% of the study area) was due to poor weather conditions and limited days of availability within the survey window due to a US Federal Government shutdown. Combined annual average survey coverage for 2011 and 2012 was $60 \%$.

The most commonly detected turtle species was loggerhead $(\mathrm{n}=3022 ; 86.6 \%)$, followed by green $(\mathrm{n}=195 ; 5.5 \%)$ and leatherback $(\mathrm{n}=110 ; 2.8 \%$; Fig. 2). There were very few Kemp's ridley turtles detected $(\mathrm{n}=28 ; 0.7 \%)$. Less than $5 \%$ of the detections were recorded as unidentified turtles $(\mathrm{n}=172)$. There were 3933 unique turtle detections during the project, $3394(86 \%)$ of which were loggerhead tur- tles (Table 2). The majority of turtle detections $(99 \%)$ were of solitary animals. Group size was missing for one record, and since most turtle detections were of a single animal, we assigned this record a group size of one. There were 406 duplicate detections (e.g. where both teams reported the same sighting). Team 1 , with a greater area of view, reported $66.1 \%$ of all turtles detected and $66.4 \%$ of loggerheads (Table 2).

For Team 1 (one right and one left window observer) the number of detections within $100 \mathrm{~m}$ of the trackline was substantially lower than the numbers detected between 100 and $200 \mathrm{~m}$ from the trackline (Fig. S1 in the Supplement). This is not uncommon in aerial surveys where it is difficult to see directly below the plane. The hazard rate form used for the DS model required that detection be at a maximum on the trackline. Detections were highest within $100 \mathrm{~m}$ of the trackline for Team 2 (one belly window observer and one right or left window observer), which alleviated the concern when the data were pooled (Fig. S1). The detection functions we used for loggerhead turtles and for all species combined were nearly identical since the vast majority of turtle detections were loggerheads. We truncated detections at $300 \mathrm{~m}$ to avoid a long tail in the detection function, thus allowing a better fit for the models (Buckland et al. 2001).

Mean $( \pm$ SD) encounter rates for sea turtle detections by stratum ranged from a low of $0.007 \pm$ 0.43 detections $\mathrm{km}^{-1}$ in stratum $\mathrm{E}$ during the fall 2011 survey period to a high of $0.389 \pm 0.12$ detections $\mathrm{km}^{-1}$ in stratum $\mathrm{C}$ during the spring 2012 survey period. Mean detection rates averaged across all strata by survey period ranged from a low of $0.064 \pm$ 0.13 detections $\mathrm{km}^{-1}$ in fall 2011 to $0.255 \pm 0.09$ detections $\mathrm{km}^{-1}$ in spring 2012 .

The MR detection function, used in abundance and density estimations, defined the probability of detection by one team given detection by the other team. AIC scores supported including the variables 'perpendicular distance from trackline (distance), ' 'team,' and an interaction term between 'distance' and 'team' in the final model for MR (Table S2 in the Supplement). For environmental data, the variables, glare and turbidity had numerous missing values and were not able to be used in the model, and AIC scores for cloud cover, sea surface temperature, and overall sighting quality did not support inclusion of environmental variables as model parameters. Summaries of environmental observations at the time of loggerhead turtle detections are included in Tables S3 \& S4 in the Supplement. We found that the 


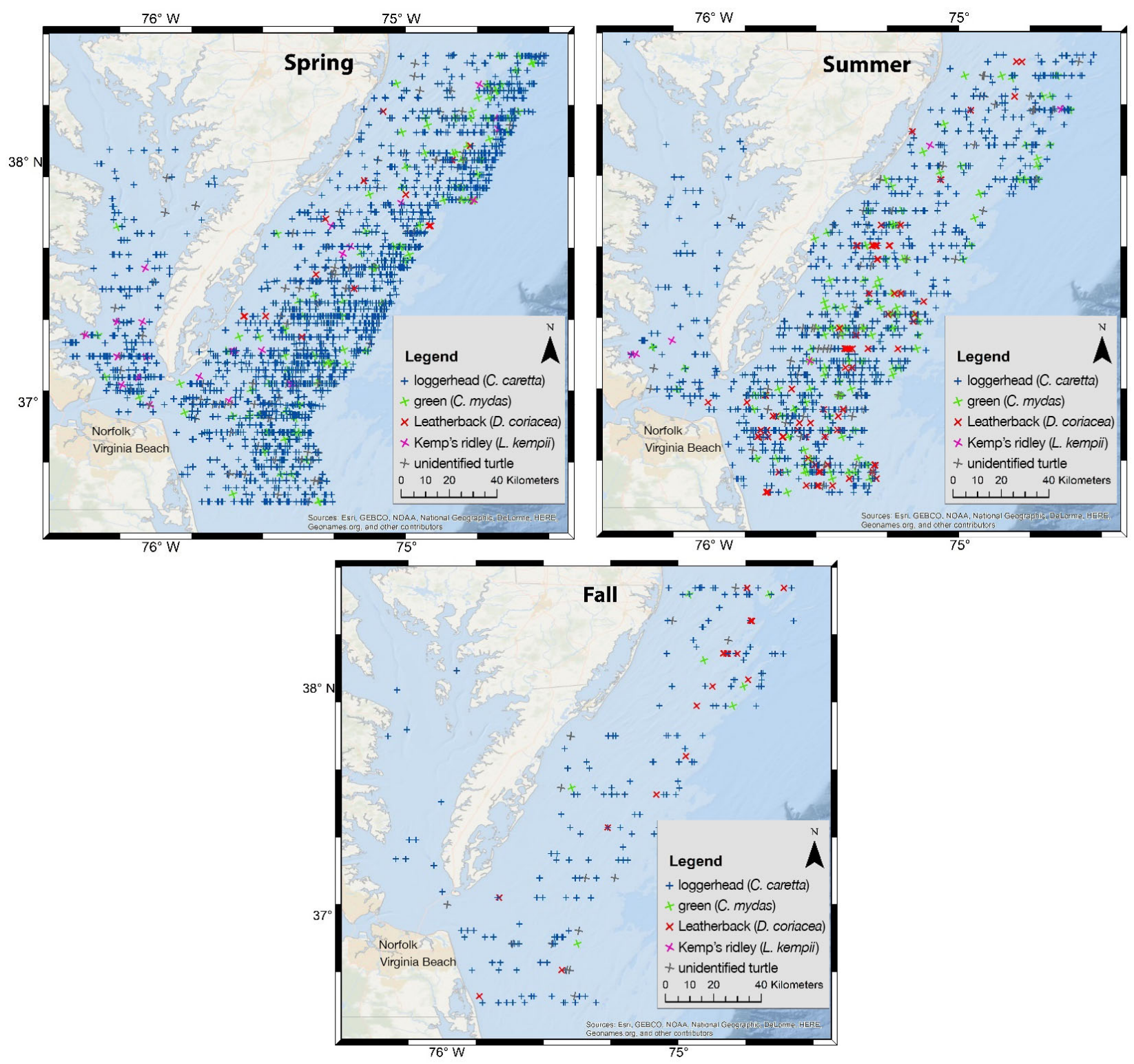

Fig. 2. Sea turtle detections by season for 2 yr of surveys (2011 and 2012). Effort was not equal among the seasons: 2 sets of surveys were flown in spring (May/Jun; $\mathrm{n}=6637 \mathrm{~km}$ trackline), 2 in summer (July/Aug; $\mathrm{n}=9266 \mathrm{~km}$ trackline) and one in fall

(Sep/Oct; $\mathrm{n}=3412 \mathrm{~km}$ trackline). Note the north-south gradient of sightings in Chesapeake Bay (on the left of the maps)

probability of detection by Team 2 (one side and one belly observer), given detection by Team 1 (2 side observers), decreased with perpendicular distance. This was expected since the visibility of the belly observer on Team 2 decreased with distance from the trackline, unlike visibility from the side windows. Thus, half of Team 2 had a limited field of view at extended distances. The probability of detection by Team 1, given detection by Team 2, increased away from the trackline and then decreased after $200 \mathrm{~m}$ (Fig. S2 in the Supplement).

\section{Estimating availability bias}

\section{Detection trials}

Of the 5 buoy systems used for the detection trial, one (depth $=1.5 \mathrm{~m}$ below surface) was eliminated from final analysis due to the turtle model breaking free from the buoys mid-trial, and several detections not including an angle of inclination. This left a total of 54 detections, with each of the 4 observers reporting 2 to 5 detections for each buoy system, and 10 to 
16 detections for each of the 4 buoy systems. The center (belly window) observer had the highest number of detections because that position could detect buoys on either side of the aircraft. We calculated distance from trackline to the buoy for each detection and truncated the data at $200 \mathrm{~m}$ where detection functions from the survey suggested that detection rate was highest. The buoy system with no model turtle present had $100 \%$ correct detections (e.g. 10 of 10 detections observed no turtle), with successively fewer correct detections for the models as depth increased. Observers correctly detected the turtle at target depth $0.5 \mathrm{~m}$ (average depth $0.6 \mathrm{~m}$ ) $93 \%$ of the time (e.g. 14 of 15 detections correctly detected 1 turtle). The models at target $1.0 \mathrm{~m}$ (average depth $1.2 \mathrm{~m}$ ) and target $2.0 \mathrm{~m}$ (average depth $2.2 \mathrm{~m}$ ) were detected correctly $54 \%$ (e.g. 7 of 13 detections reported 1 turtle) and $6 \%$ (e.g. 1 of 16 detections reported 1 turtle present) of the time, respectively. Secchi depths recorded at the buoy systems ranged from 1.1 to $1.7 \mathrm{~m}$. Secchi depths recorded $22 \mathrm{~km}$ from shore of the mouth of Chesapeake Bay ranged from 2.97 to $3.67 \mathrm{~m}$ at $20 \mathrm{~m}$ depth, illustrating greater water clarity in the ocean strata and the potential for increased detection of turtles. With Secchi depth as the primary means of comparing water clarity between the bay and ocean strata, we used data on percent correct detection as a guideline in assigning criteria for shallow, moderate, and deep detection depth ranges within which observers could detect turtles. Other surveys have used similar methods with animalshaped Secchi disks (Westgate et al. 2014, Fuentes et al. 2015).

\section{Telemetry}

For the survey window analysis, there were significant differences in mean surface times among the 4 time frames investigated using the shallow detection depth range (Friedman rank sum test, $\chi^{2}=11.4$, $\mathrm{df}=3, \mathrm{p}=0.010$ ), but the post hoc Nemenyi comparisons did not detect specific differences using the adjusted $p$-value of 0.008 at $\alpha=0.05$. Given this result, we chose to include all filtered dive summary data collected during a given survey season to calculate surface time for use in availability bias estimates.

We collected 7459 dive summaries recorded in May through October from 2011 to 2015. After time and location filters were applied to the data, 1398 dive summaries transmitted from 27 loggerhead turtles were available for availability bias calculations (Table S5 in the Supplement). Because not every turtle transmitted 
from both the ocean and Chesapeake Bay in every season, the stratified seasonal calculations included data from 8 to 10 turtles each. After eliminating repeated measures from the data, there were 5 to 7 turtles per treatment for each seasonal comparison (Table S6 in the Supplement). Analysis of seasonal differences for the deep detection depth range ( 0 to $2 \mathrm{~m}$ in bay strata and 0 to $3 \mathrm{~m}$ in the ocean strata), which included all possible depths of detection, illustrated that there were significant differences in seasonal availability in both the bay and ocean strata (Kruskal-Wallis, bay: $\chi^{2}=7.86, \mathrm{p}=$ 0.020; ocean: $\chi^{2}=12.10, p=0.002$ ). In Chesapeake Bay, availability in the deep detection depth range decreased from spring through fall, and Tukey-Kramer (Nemenyi) post hoc comparison revealed a marginally significant difference between availability in fall compared to summer $(\mathrm{p}=$ 0.0160 where p-value using Bonferroni adjustment at $\alpha=0.05$ was 0.0167 ). In the ocean, availability in the deep detection depth range varied seasonally with significantly lower availability in fall compared to summer ( $p=0.002$; Fig. 3$)$. All of the detection depth ranges in the ocean strata exhibited differences among the seasons (shallow: $\chi^{2}=11.41, \mathrm{p}=0.0033$; moderate: $\chi^{2}=$ 14.12, $\mathrm{p}=0.0009$; deep: $\chi^{2}=18.07, \mathrm{p}=$ 0.0003) but post hoc comparisons only showed a trend toward lower availability in fall compared to summer.

For our comparison of surface time between wild and rehabilitated individuals, there were 2 strata-season combinations where the number of wild and rehabilitated turtles (W/R) were similar: ocean stratum in fall $(\mathrm{W} / \mathrm{R}=4 / 5)$ and bay stratum in spring $(\mathrm{W} / \mathrm{R}=5 / 5)$. The largest sample size available for this comparison was from the ocean stratum in spring $(W / R=8 / 4)$. Mean individual surface times of rehabilitated turtles were higher than wild turtles, but there were no statistically significant differences between the 2 groups (ocean-fall: $\mathrm{W}=16, \mathrm{p}=0.19$; bay-spring: $\mathrm{W}=15, \mathrm{p}=$ 0.69 ; ocean-spring: $\mathrm{W}=19, \mathrm{p}=0.68$ ).

\section{Abundance estimates}

Density varied spatially and temporally as well as with shallow, moderate, and deep detection depth

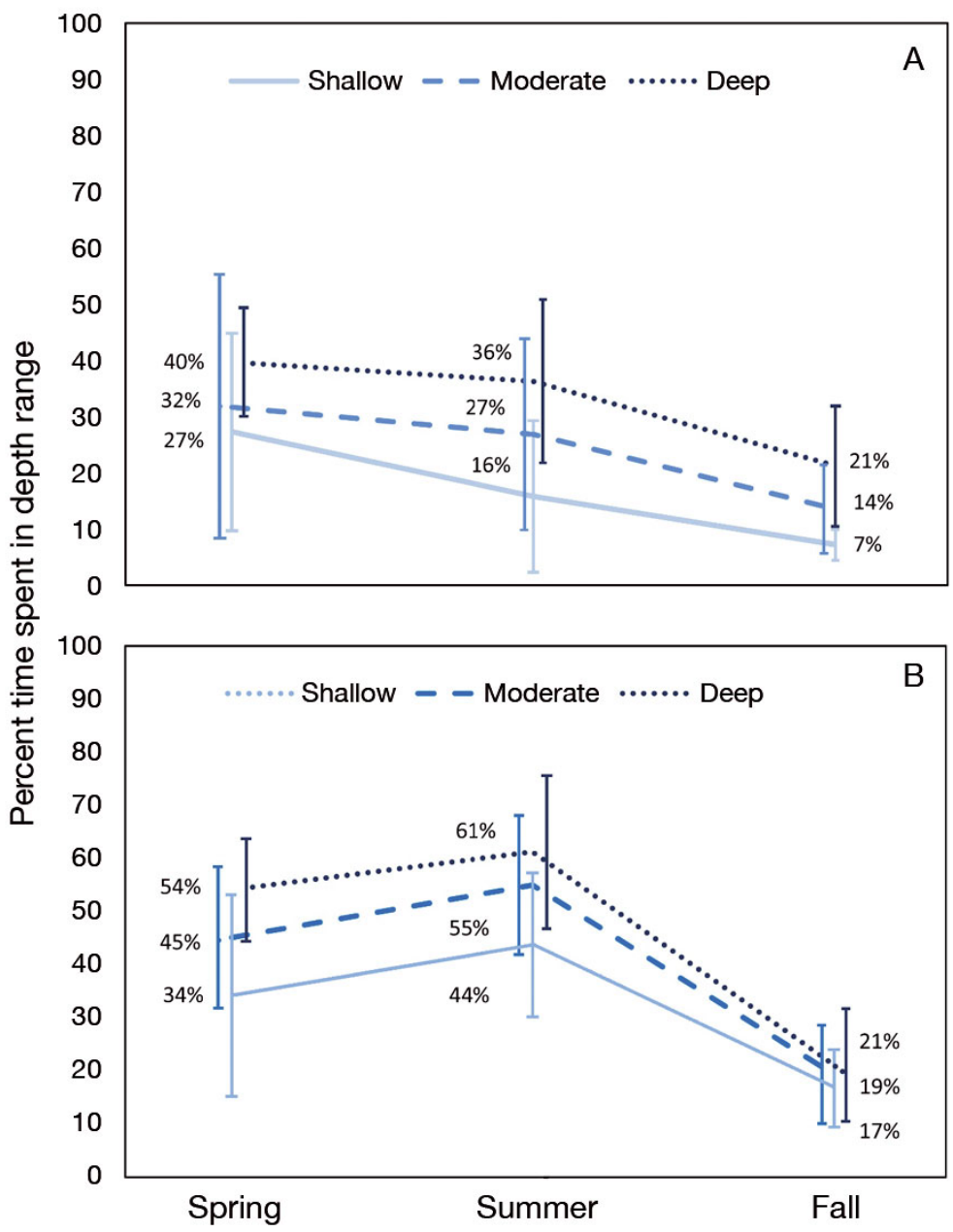

Fig. 3. Seasonal availability (mean $\pm \mathrm{SD}$ ) calculated using satellite telemetry from loggerhead turtles. Availability was calculated for 3 detection depth ranges based on the estimated maximum distance below the surface that observers could detect a turtle in (A) the bay strata (shallow = at surface; moderate $=0$ to $1 \mathrm{~m}$; deep $=0$ to $2 \mathrm{~m}$ ) compared with (B) ocean strata (shallow $=0$ to $1 \mathrm{~m}$; moderate $=0$ to $2 \mathrm{~m}$; deep $=0$ to $3 \mathrm{~m}$ )

availability corrections. The lowest corrected density was 0.59 turtles $\mathrm{km}^{-1}$ of trackline $(0.76 \mathrm{CV})$ which was the deep detection depth range correction in Chesapeake Bay in spring, and the highest was 3.32 loggerheads $\mathrm{km}^{-1}$ of trackline for the shallow detection depth range in the ocean in spring $\left(0.57 \mathrm{CV}_{\text {; }}\right.$ Table 3 and Table S7 in the Supplement). Encounter rates for the fall survey in the Chesapeake Bay strata were too low for calculations of density or abundance, regardless of availability corrections. Estimates were generally higher in the ocean strata compared with the Chesapeake Bay strata and higher in spring than summer or fall (Table 3 ). Abundance estimates stratified by season and water body and corrected for availability using the shallow detection depth availability estimates were 2.3 to 6.3 times 


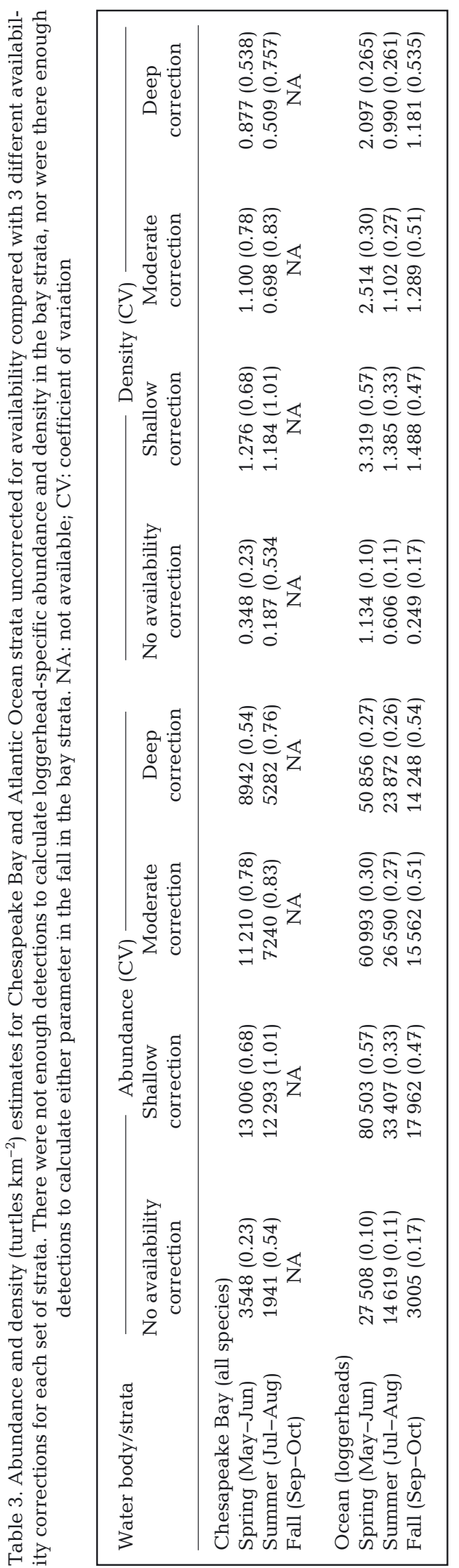

higher than uncorrected estimates, with the greatest differences in Chesapeake Bay in summer and ocean in fall. Differences between corrected and uncorrected abundance estimates decreased as the detection depth range used for availability increased (Table 3, Table S7). This trend supports the assumption that if turtles are detectable at deeper depths, fewer turtles will be unavailable for detection and the magnitude of the correction will decrease. Abundance estimates corrected for availability using the deep detection depth range were 1.6 to 4.7 times greater than uncorrected values.

Regardless of availability correction applied, differences in the spring and summer abundance and density in the ocean strata appear to be substantial since there was no overlap in the $95 \%$ confidence limits (CLs) (Table S7). Despite less survey effort, fall estimates may also be different as the overlap between fall and summer is minimal even though the fall surveys had a CV nearly twice that of spring and summer (Table 3). There was considerable overlap in $95 \%$ CLs for spring and summer estimates in Chesapeake Bay, suggesting that there was minimal difference between the 2 seasonal estimates.

\section{DISCUSSION}

The loggerhead turtle abundance estimates reported here are the first to incorporate both perception and availability bias for line transect distance sampling surveys conducted in the MAB. The US Cetacean and Turtle Assessment Program (CETAP) surveys were conducted on the continental shelf and slope of the northeast US (Cape Hatteras to Nova Scotia, Canada) from 1979 to 1981 (Shoop \& Kenney 1992). Transects extended from shore to within $10 \mathrm{~km}$ of the 1000 fathom $(1829 \mathrm{~m})$ isobath CETAP abundance and density estimates did not incorporate corrections for perception or availability bias in the survey design. Uncorrected loggerhead abundance estimates were within the range of 2200 to 11000 with density estimates of 0.00164 to 0.510 loggerheads $\mathrm{km}^{-2}$ for the entire region surveyed (Shoop \& Kenney 1992). The CETAP survey reported their highest loggerhead turtle abundance of 4236 turtles for the region corresponding to the ocean strata in our survey on a date (23 June 1980) roughly corresponding to the timing of our spring surveys (late May to mid-June; Shoop \& Kenney 1992). Uncorrected loggerhead turtle abundance for our spring surveys in the ocean strata of our project ranged from 9082 in 2011 to 16489 in 2012. The difference in 
uncorrected abundance estimates over the approximately 30 yr time span between surveys appears to be striking, but is influenced both by differences in survey design and implementation as well as by potential differences in loggerhead turtle abundance. CETAP surveys were conducted at a higher altitude $(229 \mathrm{~m})$ and a greater speed $\left(222 \mathrm{~km} \mathrm{~h}^{-1}\right)$ than our surveys, and it was estimated that observers were incapable of detecting turtles $<75 \mathrm{~cm}$ in length (Shoop \& Kenney 1992). In contrast, National Marine Fisheries Service (NMFS) scientists estimated that the minimum turtle size detectable with the platform and parameters (183 m altitude) used in our survey was $40 \mathrm{~cm}$ (L. Garrison pers. comm.). Although this is a significant difference in turtle size, the mean $( \pm \mathrm{SD})$ minimum SCL of fresh to moderately decomposed stranded loggerhead turtles in Virginia from 2010 to $2014(\mathrm{n}=225)$ was $70.5 \pm 12.2 \mathrm{~cm}$ and the mean minimum SCL of loggerheads that stranded on ocean beaches (compared with inshore) was $76.7 \pm 14.1 \mathrm{~cm}$, with a range of 48.3 to $104.5 \mathrm{~cm}$ (Virginia Aquarium unpubl. data). We believe that the size of stranded loggerhead turtles reflects the size of live turtles that live and die in the waters of the region. The data on turtle size suggest that most of the loggerhead turtles seen in coastal ocean waters are larger than $62 \mathrm{~cm}$ minimum SCL (62 cm = mean - $1 \mathrm{SD})$. Personal experience of the lead author (S. G. B.) from offshore turtle captures suggests that the size of loggerhead turtles in MAB offshore is similar to, if not greater than stranded turtles. Since both the 75 and $40 \mathrm{~cm}$ size minimums for the surveys were estimated, the difference between actual turtle size detectability is unknown. The estimates of minimum turtle size detected for these 2 surveys highlight the need for more research into detectability from aerial platforms, in addition to the critical importance of incorporating perception and availability bias corrections including other aspects of turtle visibility such as sub-surface detection depth and detection size limits. Long-term trends in population status may be more fully understood through comparison of results from studies using methodology that incorporates sub-surface and minimum size detection corrections.

Our results will be more directly comparable with final estimates from broad-scale surveys of the MAB from the ongoing multi-agency AMAPPS project. Our surveys used the same methodology and aircraft as the AMAPPS surveys as well as similar tag programming for availability bias estimates. The primary differences between our survey and the AMAPPS surveys in the MAB were transect length, distance between transects, and effort. The AMAPPS surveys had longer transects that were $20 \mathrm{~km}$ apart, and our surveys had greater effort within the MAB (NMFS 2011c). The AMAPPS surveys did not include the inland waters of Chesapeake Bay, but a preliminary estimate of loggerhead abundance adjusted for perception and availability from AMAPPS data for the area referred to as Mid-Atlantic South (Cape Hatteras, North Carolina to mid-New Jersey) was 42 021, which was corrected using a mean availability correction of $67.1 \%$ (36 666 lower quartile, 49816 upper quartile using upper and lower availability corrections of 56.6 and $76.9 \%$ respectively; NMFS 2011c). The area of this stratum was $62104 \mathrm{~km}^{2}$, yielding a density estimate of 0.677 turtles $\mathrm{km}^{-2}$ (0.590, 0.802 lower, upper quantile loggerhead turtles $\mathrm{km}^{-2}$ ). The AMAPPS surveys were flown in the second week of August 2010 and their preliminary density estimate was lower than our density estimate for loggerheads in the ocean strata during the summers of 2011 and 2012. Our surveys resulted in density estimates of 1.102 (0.886 to $1.37395 \% \mathrm{CL}$ ) and 1.385 (1.113 to $1.72595 \% \mathrm{CL}$ ) turtles $\mathrm{km}^{-2}$ using availability corrections of 43.8 and $55.5 \%$ respectively (Table $\mathrm{S} 7$ ). If we apply the availability correction used by AMAPPS (67.1\%), our density decreases to 0.903 loggerhead turtles $\mathrm{km}^{-1}$, still higher than the AMAPPS preliminary estimate. The AMAPPS estimate was developed from $1 \mathrm{yr}$ of aerial survey and tagging data, and the authors stated that more work was required in order to refine the estimates. Differences between the preliminary AMAPPS density estimates and our results suggest either an underestimate of abundance in the 2010 AMAPPS surveys, lower density in the parts of the AMAPPS Mid-Atlantic South study that are outside of the study area for our project, or a combination of the two. Another possible source of disparity between the 2 surveys is the ratio of unidentified hardshell turtles to loggerhead turtles. In the AMAPPS 2010 survey, there were 181 loggerhead detections and 217 unidentified hardshell turtle detections, $66 \%$ of which were added to the loggerhead data (NMFS 2011c). In the summer surveys for our project, there were 411 loggerhead detections and 15 unidentified hardshell turtle detections. The higher ratio of unidentified hardshell detections in the 2010 AMAPPS data may have led to an underestimate of loggerhead density. Nearly $90 \%$ of all unique hardshell turtle detections in our final survey dataset (3394 of 3814) were loggerhead detections. If the percentage was similar for the larger Mid-Atlantic South study area of the AMAPPS survey, using only $66 \%$ of the unidentified hardshell detections in the loggerhead abundance calculations would have led to an underestimate. 
Historic data on abundance of sea turtles in the Chesapeake Bay from VIMS are also available for comparison. Surveys conducted in Chesapeake Bay between 1982 and 1987 (Byles 1988) and from 2001 to 2004 (Mansfield 2006) used line transect distance sampling techniques with 2 observers (left and right) in a single engine high-wing aircraft. A total of 60 east-west oriented transect lines were established, 24 of which were regularly flown during both survey periods. Flights were weekly or twice weekly from spring through fall, and seasons were assigned postsurvey. Conservative annual abundance estimates corrected for availability using $25 \%$ surface time in spring and $5.3 \%$ in summer and fall in lower Chesapeake Bay ranged from $2432 \pm 2261$ to $4528 \pm 3288$ turtles in the 1982 to 1987 study, and from $799 \pm 801$ to $1600 \pm 1040$ turtles in the early 2000s (Table 4; Mansfield 2006). The difference in abundance estimates between the 2 VIMS studies represents a nearly $60 \%$ decline in turtle abundance in the lower Chesapeake Bay in less than 2 decades (Mansfield 2006). The Chesapeake Bay study area $\left(1300 \mathrm{~km}^{2}\right)$ in the Byles (1988) and Mansfield (2006) studies corresponded in size and location to stratum D in our survey (1587 to $1687 \mathrm{~km}^{2}$ ).

Uncorrected sea turtle density estimates based on turtles detected by Team 1 only in stratum D in spring and summer of 2011 and 2012 were 1.5 and 4.0 times higher than Mansfield's (2006) highest uncorrected estimate, respectively. Uncorrected density estimates from our study were more similar to those from the 1980s than those from the early 2000s (Table 4). Differences in survey design and methodology may explain the difference among estimates derived from earlier surveys and our current estimates. For example, the VIMS aircraft flew at a lower altitude (152 m compared to $183 \mathrm{~m})$ and slower speed $\left(130 \mathrm{~km} \mathrm{~h}^{-1}\right.$ compared to $175 \mathrm{~km} \mathrm{~h}^{-1}$ ) than the Twin Otter used in this survey. Surveys in the VIMS studies were flown continually each week of the sea turtle season, whereas the surveys in this project were flown in discrete seasonal blocks. Finally, the Twin Otter was outfitted with bubble windows and the VIMS aircraft was not. All other variables being similar, lower speed and altitude during the VIMS surveys should result in a higher number of detections since both surveys were based on a truncated strip width of $300 \mathrm{~m}$. The use of bubble windows in the Twin Otter, however, effectively increased the strip width directly below the aircraft, which was not the case in the VIMS surveys. If the differences in abundance estimates between the 2 surveys were real, perhaps the decline in sea turtle abundance observed by Mansfield (2006) during surveys from 2001 to 2004 was wholly or partially due to a distributional shift from Chesapeake Bay into ocean waters, which were not surveyed in the 2001 to 2004 study. Our ability to interpret population trends based on historic surveys and our survey in the Chesapeake Bay is hindered by the differences in survey methodologies. This underscores the importance of establishing consistent survey methods that incorporate bias corrections for long-term monitoring of populations.

Availability correction becomes more important for animals that appear at the surface in small groups or alone, as well as for animals with extended dive times compared with time at the surface (Buckland et al. 2004). As air-breathing marine fauna, sea turtles are referred to as 'surfacers', spending greater than 50\% of their time subsurface in comparison to 'divers', which spend most of their time at or above the surface (Kooyman 1989). In some habitats and temperature conditions, however, sea turtles behave more like divers, spending extended times at the surface (Hochscheid et al. 2010). 
There was no significant difference in surface time between turtles that were wild (directly captured or by-caught) and those that stranded alive and were rehabilitated, tagged, and released. Our ability to detect a difference may have been compromised because sample size was low and variance was high. There is substantial individual variability in surface time among wild-caught individuals (NMFS 2011c); thus, individual variability in surface time may be normal and not a result of including rehabilitated and released turtles in the analyses. Cardona et al. (2012) noted differences between rehabilitated/released and wild/control turtles in surface time at night, but did not find differences in daylight surface time, which we used in our study for availability bias correction. Inclusion of rehabilitated animals enhanced our data set by increasing the number of individual turtles for availability correction, but it is important to acknowledge the potential for introducing bias in the availability data.

In spring and summer of a temperate habitat in the Mediterranean, Cardona et al. (2005) calculated mean surface time (time tags were dry) as $35.1 \pm 19.7 \%$ among 5 juvenile loggerheads that ranged from 37.1 to $48.7 \mathrm{~cm}$ carapace length, and this estimate was used to correct aerial survey data for the same area (Gómez de Segura et al. 2006). Cardona et al. (2005) found that smaller individuals spent more time at the surface. Thomson et al. (2013) tagged sub-adult and adult loggerhead and green turtles in a year-round, sub-tropical foraging ground in Shark Bay, Australia and found that larger corrections were required when turtles were in deeper, cooler water compared to shallower, warmer water. The Shark Bay study found that applying uniform availability correction factors led to overestimation of abundance in shallower, warmer habitat and underestimation of abundance in deeper, cooler habitat (Thomson et al. 2013). Peckham et al. (2012) estimated that juvenile and sub-adult loggerheads in the Gulf of Ulloa off Baja California Sur, Mexico spent $13 \%$ of their time at the surface and $39 \%$ of time within $2 \mathrm{~m}$ of the surface, and Seminoff et al. (2014) used the latter as an availability correction for aerial surveys in the region. Finally, availability for immature and adult green turtles was calculated using time-depth recorder (TDR) data from 4 different sites, 3 in Queensland, Australia and 1 from the Gulf of California in Mexico (Fuentes et al. 2015). Two depth strata, 0 to $1 \mathrm{~m}$ and 0 to $2.5 \mathrm{~m}$, were determined using turtle Secchi disks in different habitats and conditions; the resulting surface time estimates were $5 \pm$ $1 \%$ (SE) for the shallower depth range and $18 \pm 2 \%$ for the deeper range (Fuentes et al. 2015). Mansfield
(2006) found that time spent at or near the surface by loggerhead and Kemp's ridley turtles in Chesapeake Bay was highest in spring and decreased as water temperatures increased in the summer. She found that surface time in spring ranged from 9 to $25 \%$, and used the higher $25 \%$ surface time as a correction for spring while applying an estimate of $5.3 \%$ surface time (Byles 1988) for summer and fall. Differences between summer and fall were not investigated nor were species specific availability estimates developed.

We found that surface time was higher in the ocean strata in summer than in either spring or fall. Lack of significant differences in surface time between spring and other seasons in the ocean strata may be related to turtles' migratory status and end points. In a review of sea turtle diving behavior and physiology, Hochscheid (2014) reported that studies have repeatedly shown that sea turtles make use of shallower depths (2.5 to 3.0 times body thickness) when migrating. Hochscheid et al. (2010) also propose the idea that extended surface times may serve to replace oxygen debt from long foraging dives instead of, or along with, serving as a means of thermal regulation. If correct, then fewer deep foraging dives by migrating turtles in spring may explain why surface times were not higher in our study.

Although previous studies have investigated seasonal differences in abundance and distribution of sea turtles at sites inhabited year-round (Thomson et al. 2013), ours is the first study to present availability bias-corrected abundance estimates for loggerheads in the seasonally important temperate shelf waters of the MAB. Temporal differences in abundance estimates of the ocean strata in our study underscore the need for multiple years and seasons of data to develop robust abundance estimates for sea turtle populations at mid-latitudes, and to assess how abundance may change over time. Migratory behavior of turtles could have contributed to the seasonal differences observed in surface time in the ocean strata. For example, turtles migrating to endpoints north of our study area in spring may be making shallow dives above the thermocline as they travel and may not be spending significant time foraging below the thermocline. Behavioral differences such as these could result in different physiological requirements at the surface, such as temperature and/or lactic acid regulation for foraging turtles compared with only respiration for shallow diving, traveling turtles (Hochscheid et al. 2010). Future analyses of dive data for turtles assigned to different behavioral states using switching state space analyses may provide more insight into why surface time for loggerheads 
was lower in spring than in summer. Viewing our data in the context of the broader AMAPPS survey effort will also provide additional information on seasonal patterns of migratory sea turtles.

Density gradients apparent in the detection data may have contributed to the relatively high CVs in the Chesapeake Bay strata (see Fig. 2). Specifically, density was consistently lower in the northern stratum (stratum E) compared to the southern stratum (stratum D) of the bay. This north-south gradient was also reflected in loggerhead stranding data for Chesapeake Bay. In an unpublished analysis of sea turtle strandings in VA and MD from 1998 to 2012, $4 \%$ of loggerhead strandings occurred in the MD portion of Chesapeake Bay, $13 \%$ in the (VA) midBay, $45 \%$ in the (VA) lower Bay, and $38 \%$ along ocean beaches (Virginia Aquarium unpubl. data). This trend has continued in the recent past. Most likely, this density gradient reflects the distribution and/or availability of preferred loggerhead prey. Given that transects were oriented east-west, the north-south density gradient, which was obvious in all seasons, increased the variance among tracklines and may have resulted in an underestimate of abundance in these 2 strata (Buckland et al. 2004, Marques et al. 2013). An east-west density gradient was apparent in the ocean strata in spring, with consistently higher numbers of detections at the east ends of the tracklines compared to the west ends, but this would not have caused higher variance with eastwest oriented tracklines. It is interesting to note that in all seasons, detections tended to increase rather than decrease as the eastern end of the trackline was approached, suggesting that turtles were consistently present offshore (along the eastern edges) of the survey area (see Fig. 2).

Selection of detection depth ranges for calculating surface time and availability correction has important implications for abundance estimates. We chose to present a range of availability corrections to illustrate that variation in sea turtle availability is not only heterogeneous by depth and habitat, but also by observers' ability to detect animals sub-surface (Fuentes et al. 2015, Alves et al. 2016). Mansfield (2006) assumed a $0.5 \mathrm{~m}$ depth for her surface time estimates from radio and sonic telemetry studies in the early 2000s. Aerial surveys for that project were only conducted in Chesapeake Bay, where water clarity was lower than the Atlantic Ocean, and the surface time estimate used ( $25 \%$ in spring) was similar to our bay strata estimate of $27 \%$ for the shallow detection depth range. Even in Chesapeake Bay, however, water clarity varies temporally with season and stochastically with runoff events due to rainfall (Gallegos et al. 2005). Water clarity also varies spatially with proximity to river mouths and other sources of terrestrial effluent. The latter cause of spatial variation in water clarity is difficult to quantify because it is largely due to inorganic particulates carried from land instead of predictable plankton population changes (Gallegos et al. 2011). Temporal and spatial variation in water clarity in the estuarine environment of Chesapeake Bay suggests to us that the best practice of determining the depth at which observers can detect turtles would be to measure turtle Secchi depth as described in Fuentes et al. (2015), but add a size variable, such as the detection trial conducted by Epperly et al. (1995), on each day of the survey. This type of detection analysis would be both expensive and logistically challenging and is unlikely to be funded for every survey that is conducted, but would constitute a best case scenario.

Thomson et al. (2013) addressed the heterogeneity of availability estimates by modeling surface time temporally over seasons and spatially with environmental covariates, primarily water depth and temperature. Fuentes et al. (2015) was the first sea turtle study to incorporate sub-surface detection depth into availability calculations, finding that environmental conditions affected the depths at which observers could detect turtle models. Our study accounted for environmental variables by inclusion in initial models, although low AIC scores ultimately resulted in selection of models that did not include environmental data. Although our sub-surface detection trials were not as extensive as originally planned due to logistic difficulties, the trials did provide valuable data on detection depth that could be used to generate abundance estimates using shallow, moderate, and deep detection depth criteria. We recommend that surface time estimation for future sea turtle surveys in Chesapeake Bay and similar areas include 3 components: (1) a range of detection depths in various strata, (2) a range of detection depths under variable survey conditions, and (3) detection trials with different target sizes that mimic the different species and/or life stages in the region.

\section{CONCLUSIONS}

Our fine-scale surveys and the resultant abundance estimates, which correct for perception and availability biases, serve as a useful baseline for future studies of sea turtle abundance in Chesapeake Bay and the southern MAB. These data may also be 
compared with broad-scale AMAPPS efforts to develop seasonal abundance estimates for western North Atlantic loggerhead turtles. Results of our study contribute to efforts to monitor sea turtles in this region and provide critical data on sea turtle baseline abundance for regional management and conservation efforts, while providing further caveats for use of uniform availability corrections applied to studies that vary spatially and temporally.

Acknowledgements. This work was conducted under NMFS Endangered Species permits \#16134 issued to W.M.S. and \#15575 issued to R.A.D. Jr. Funding was provided by the NOAA Species Recovery Grants to States program (Award \#NA47200033) issued to the Virginia Department of Game and Inland Fisheries which contracted with the Virginia Aquarium \& Marine Science Center Foundation. Additional funding for tags and turtle capture was also provided by US Fleet Forces Command as well as the Virginia Aquarium Batten Collaborative Research Fund and Batten Professional Development Fund. We appreciate the support of Virginia Aquarium staff, interns and volunteers, Riverhead Foundation aerial observers, and NAVFAC Atlantic staff for data collection, field capture, and tagging assistance. We also thank the Coonamesset Farm Foundation and NOAA Fisheries NE Fisheries Science Center for including us in collaborative research efforts and providing a platform of opportunity for tagging turtles on the scallop boat fleet.

\section{LITERATURE CITED}

Alves MDO, Schwamborn R, Borges JCG, Marmontel M, Costa AF, Schettini CAF, Araújo ME (2013) Aerial survey of manatees, dolphins and sea turtles off northeastern Brazil: correlations with coastal features and human activities. Biol Conserv 161:91-100

Alves M, Kinas P, Marmontel M, Borges J, Costa A, Schiel N, Araújo M (2016) First abundance estimate of the Antillean manatee (Trichechus manatus manatus) in Brazil by aerial survey. J Mar Biol Assoc UK 96:955-966

Arendt M, Segars A, Byrd J, Boynton J, Schwenter J, Whitaker J, Parker L (2012) Migration, distribution, and diving behavior of adult male loggerhead sea turtles (Caretta caretta) following dispersal from a major breeding aggregation in the Western North Atlantic. Marine Biology 159:113-125

* Barco S, Law M, Drummond B, Koopman H and others (2016) Loggerhead turtles killed by vessel and fishery interaction in Virginia, USA, are healthy prior to death. Mar Ecol Prog Ser 555:221-234

Borchers DL, Zucchini W, Heide Jørgensen MP, Cañadas A, Langrock R (2013) Using hidden Markov models to deal with availability bias on line transect surveys. Biometrics 69:703-713

Buckland S, Anderson D, Burnham K, Laake J, Borchers D, Thomas L (2001) Introduction to distance sampling: estimating abundance of biological populations. Oxford University Press, Oxford

Buckland S, Anderson D, Burnham K, Laake J, Borchers D, Thomas L (2004) Advanced distance sampling: estimating abundance of biological populations. Oxford University Press, Oxford
Byles RA (1988) The behavior and ecology of sea turtles in Virginia. PhD dissertation, Virginia Institute of Marine Science, College of William and Mary, Gloucester Point, VA

Cardona L, Revelles M, Carreras C, San Felix M, Gazo M, Aguilar A (2005) Western Mediterranean immature loggerhead turtles: habitat use in spring and summer assessed through satellite tracking and aerial surveys. Mar Biol 147:583-591

* Cardona L, Fernández G, Revelles M, Aguilar A (2012) Readaptation to the wild of rehabilitated loggerhead sea turtles (Caretta caretta) assessed by satellite telemetry. Aquat Conserv 22:104-112

Casale P, Tucker AD (2017) Caretta caretta (amended version of 2015 assessment). The IUCN Red List of Threatened Species 2017: e.T3897A119333622. www.iucnredlist.org/ species/3897/119333622

Ceriani SA, Roth JD, Evans DR, Weishampel JF, Ehrhart LM (2012) Inferring foraging areas of nesting loggerhead turtles using satellite telemetry and stable isotopes. PLOS ONE 7:e45335

* Ceriani SA, Roth JD, Sasso CR, McClellan CM and others (2014) Modeling and mapping isotopic patterns in the Northwest Atlantic derived from loggerhead sea turtles. Ecosphere 5:art122

Coyne M, Godfrey M, Godley B, Lay K (2008) Hard shell sea turtle PTT attachment protocol. www.seaturtle.org/ documents/PTT_Attachment_Protocol.pdf

Dunn OJ (1961) Multiple comparisons among means. J Am Stat Assoc 56:52-64

Fhrhart L, Redfoot W, Bagley D, Mansfield K (2014) Longterm trends in loggerhead (Caretta caretta) nesting and reproductive success at an important western Atlantic rookery. Chelonian Conserv Biol 13:173-181

Epperly SP, Braun J, Chester AJ (1995) Aerial surveys for sea turtles in North Carolina inshore waters. Fish Bull 93: $254-261$

*Fewster RM, Buckland ST, Burnham KP, Borchers DL and others (2009) Estimating the encounter rate variance in distance sampling. Biometrics 65:225-236

Fuentes MM, Bell I, Hagihara R, Hamann M and others (2015) Improving in-water estimates of marine turtle abundance by adjusting aerial survey counts for perception and availability biases. J Exp Mar Biol Ecol 471:77-83

*Gallegos CL, Jordan TE, Hines AH, Weller DE (2005) Temporal variability of optical properties in a shallow eutrophic estuary: seasonal and interannual variability. Estuar Coast Shelf Sci 64:156-170

*Gallegos CL, Werdell PJ, McClain CR (2011) Long term changes in light scattering in Chesapeake Bay inferred from Secchi depth, light attenuation, and remote sensing measurements. J Geophys Res 116:C00H08

George RH (1997) Health problems and diseases of sea turtles. In: Lutz PL, Musick JA (eds) The biology of sea turtles, Vol 1. CRC Press, Boca Raton, FL p 363-385

* Gómez de Segura A, Tomás J, Pedraza SN, Crespo EA, Raga JA (2006) Abundance and distribution of the endangered loggerhead turtle in Spanish Mediterranean waters and the conservation implications. Anim Conserv 9:199-206

* Griffin DB, Murphy SR, Frick MG, Broderick AC and others (2013) Foraging habitats and migration corridors utilized by a recovering subpopulation of adult female loggerhead sea turtles: implications for conservation. Mar Biol 160:3071-3086

* Hays GC, Åkesson S, Godley BJ, Luschi P, Santidrian P 
(2001) The implications of location accuracy for the interpretation of satellite-tracking data. Anim Behav 61: 1035-1040

*Hochscheid S (2014) Why we mind sea turtles' underwater business: a review on the study of diving behavior. J Exp Mar Biol Ecol 450:118-136

*Hochscheid S, Bentivegna F, Hamza A, Hays GC (2010) When surfacers do not dive: multiple significance of extended surface times in marine turtles. J Exp Biol 213: 1328-1337

Innes S, Heide-Jørgensen MP, Laake JL, Laidre KL, Cleator HJ, Richard P, Stewart REA (2002) Surveys of belugas and narwhals in the Canadian High Arctic in 1996. NAMMCO Sci Publi 4:169-19

Jones TT, Van Houtan KS, Bostrom BL, Ostafichuk P and others (2013) Calculating the ecological impacts of animal-borne instruments on aquatic organisms. Methods Ecol Evol 4:1178-1186

Keinath JA, Muscik JA, Byles RA (1987) Aspects of the biology of Virginia's sea turtles: 1979-1986. Va J Sci 38: 329-336

Kooyman GL (1989) Diverse divers. Springer-Verlag, Berlin

Laake JL, Borchers DL (2004) Methods for incomplete detection at distance zero. In: Buckland ST, Anderson DR, Burnham KP, Laake JL, Borchers DL, Thomas L (eds) Advanced distance sampling. Oxford University Press, Oxford, p 108-189

Laake JL, Calambokidis J, Osmek SD, Rugh DJ (1997) Probability of detecting harbor porpoise from aerial surveys: estimating $g(0)$. J Wildl Manag 61:63-75

Lamont MM, Fujisaki I, Carthy RR (2014) Estimates of vital rates for a declining loggerhead turtle (Caretta caretta) subpopulation: implications for management. Mar Biol 161:2659-2668

Lutcavage ME, Musick JA (1985) Aspects of the biology of sea turtles in Virginia. Copeia 1985:449-456

Mansfield KL (2006) Sources of mortality, movements and behavior of sea turtles in Virginia. PhD dissertation, Virginia Institute of Marine Science, College of William and Mary, Gloucester Point, VA

Marques FFC, Buckland ST (2004) Covariate models for the detection function. In: Buckland ST, Anderson DR, Burnham KP, Laake JL, Borchers DL, Thomas L (eds) Advanced distance sampling: estimating abundance of biological populations. Oxford University Press, Oxford, p 31-47

Marques TA, Buckland ST, Bispo R, Howland B (2013) Accounting for animal density gradients using independent information in distance sampling surveys. Stat Methods Appl 22:67-80

Marsh H, Sinclair DF (1989) Correcting for visibility bias in strip transect aerial surveys of aquatic fauna. J Wildl Manag 53:1017-1024

Musick J, Limpus C (1997) Habitat utilization and migration in juvenile sea turtles. In: Lutz PL, Musick JA (eds) The biology of sea turtles, Vol 1. CRC Press, Boca Raton, FL, p 137-163

NMFS (National Marine Fisheries Service) (2011a) Endangered and threatened species; determination of nine distinct population segments of loggerhead sea turtles as endangered or threatened; final rule. Fed Regist 76: 58868-58952

NMFS (2011b) 2011 annual report to the Inter-Agency Agreement M10PG00075/0001: a comprehensive assessment of marine mammal, marine turtle, and seabird

Editorial responsibility: Paolo Casale,

Pisa, Italy abundance and spatial distribution in US waters of the western North Atlantic Ocean. Northeast Fisheries Science Center, Woods Hole, MA and Southeast Fisheries Science Center, Miami, FL

NMFS (2011c) Preliminary summer 2010 regional abundance estimate of loggerhead turtles (Caretta caretta) in northwestern Atlantic Ocean continental shelf waters. Reference Document 11-03, Northeast Fisheries Science Center. National Marine Fisheries Service, Woods Hole, MA

NMFS (2014) Final Rule: Endangered and threatened species: critical habitat for the Northwest Atlantic Ocean loggerhead sea turtle Distinct Population Segment (DPS) and determination regarding critical habitat for the North Pacific Ocean loggerhead DPS. Fed Regist 79: 39856-39912

NMFS, USFWS (US Fish and Wildlife Service) (2008) recovery plan for the Northwest Atlantic population of the loggerhead sea turtle (Caretta caretta), 2nd revision. National Marine Fisheries Service, Silver Spring, MD

Peckham SH, Abernathy K, Balazs GH, Dutton PH, Marshall G, Polovina J, Robinson P (2012) Sightability of the North Pacific loggerhead sea turtle at the Baja California Sur foraging hotspot. Final Report JF133FlOSE3013. NMFS Southwest Region, Long Beach, CA

* Pohlert T (2014) The pairwise multiple comparison of means package (PMCMR). R package https://CRAN.R-project. org/package=PMCMR

* Pollock K, Marsh H, Lawler IR, Alldredge MW (2006) Estimating animal abundance in heterogenous environments: an application to aerial surveys for dugongs. J Wildl Manag 70:255-262

Sachs L (1997) Angewandte Statistik, 8th edn. Springer, Berlin

* Seminoff JA, Eguchi T, Carretta J, Allen CD and others (2014) Loggerhead sea turtle abundance at a foraging hotspot in the eastern Pacific Ocean: implications for atsea conservation. Endang Species Res 24:207-220

Shoop CR, Kenney RD (1992) Seasonal distributions and abundances of loggerhead and leatherback sea turtles in waters of the northeastern United States. Herpetol Monogr 6:43-67

Silva RD, DeAlteris JT, Milliken HO (2011) Evaluation of a pound net leader designed to reduce sea turtle bycatch. Mar Fish Rev 73:36-45

*Thomas L, Buckland ST, Rexstad E, Laake JL and others (2010) Distance software: design and analysis of distance sampling surveys for estimating population size. J Appl Ecol 47:5-14

* Thomson JA, Cooper AB, Burkholder DA, Heithaus MA, Dill LM (2012) Heterogeneous patterns of availability for detection during visual surveys: spatiotemporal variation in sea turtle dive-surfacing behavior on a feeding ground. Methods Ecol Evol 3:378-387

Thomson JA, Cooper AB, Burkholder DA, Heithaus MA, Dill LM (2013) Correcting for heterogeneous availability bias in surveys of long-diving marine turtles. Biol Conserv 165:154-161

*Westgate AJ, Koopman HN, Siders ZA, Wong SN, Ronconi RA (2014) Population density and abundance of basking sharks Cetorhinus maximus in the lower Bay of Fundy, Canada. Endang Species Res 23:177-185

Witherington B, Kubilis P, Brost B, Meylan A (2009) Decreasing annual nest counts in a globally important loggerhead sea turtle population. Ecol Appl 19:30-54

Submitted: September 19, 2017; Accepted: July 27, 2018

Proofs received from author(s): November 19, 2018 